\title{
La interculturalidad atraviesa la cultura educativa peruana
}

\author{
Jorge Luis Yangali Vargas \\ jyangali@uncp.edu.pe \\ Universidada Nacional del Centro del Perú \\ Orcid: $0000-0003-3714-326 X$
}

El 2020 concluyó el proceso de licenciamiento, el mismo que faculta a las universidades peruanas su funcionamiento. Las primeras universidades públicas en licenciarse fueron las creadas en este nuevo siglo; algunas de las cuales tienen la denominación intercultural (Sunedu 2020). Siguiendo la política educativa de los últimos cincuenta años, la creación y, ahora, puesta en marcha de estas instituciones de educación superior busca atender, prioritariamente, a la población indígena, de modo especial a los pueblos originarios de la amazonia. Vale decir, que la universidad intercultural, es concebida como agencia que cobija y atiende a los grupos culturales y poblacionales colonizados. No obstante, el criterio ontológico reivindicador de su creación, en la compleja realidad socio-cultural de más de dos siglos de colonización promovida por el estado republicano, estas universidades interculturales están al servicio de la población colona; lo cual se evidencia en la cobertura de las vacantes de admisión y matrícula, en la lengua del cotidiano proceso enseñanza-aprendizaje y en muchas de las priorizadas prácticas culturales institucionales.

Con el objetivo de atender a los estudiantes de educación secundaria en su idioma materno en instituciones situadas en entornos interculturales, el Ministerio de Educación viene implementando el aprendizaje del idioma originario. En las instituciones educativas situadas en las ciudades, donde esta realidad lingüístico-cultural pasó desapercibida por muchos años, esta política ha provocado el reclamo por parte de los docentes (Cadena Tv 2021). Los profesores, durante su etapa de formación inicial (en universidades e institutos monoculturales) no han sido preparados para afrontar la educación bilingüe, lo que debería incidir en la evaluación y replanteamiento de los actuales planes de estudio.

Hoy, hay una labor articulada entre el Ministerio de Cultura (2015) y el Ministerio de Educación para comprometer a los gobiernos locales, regionales, la sociedad civil y las universidades en la implementación del enfoque intercultural. Esta labor multisectorial viene haciendo, principalmente por parte de los docentes, que lleven o desarrollen cursillos de corto y mediano alcance para el aprendizaje de las lenguas originarias. En el entorno regional de nuestra revista -la región Junín- por ejemplo, se han organizado cursos de asháninka, nomatsiguenga, quechua wanka, etc.

El impacto de lo jurídico (Vargas, 2017) en las políticas lingüísticas, podemos verlo en el caso anterior; así como en el brote de las propagandizadas "sustentaciones de tesis" en lenguas originarias. La inclusión de certificar el dominio de una lengua originaria, y así cumplir con uno de los requisitos para la obtención de grado académico - principalmente de doctor según la Ley 30220, ha beneficiado tanto a los hablantes nativos como a las instituciones que las enseñan.

En la cultura educativa peruana el impacto de la interculturalidad no tiene precedentes. El confinamiento por la pandemia, por ejemplo; ha obligado al Estado a transmitir los contenidos curriculares en nueve idiomas (los más hablados) a través del programa Aprendo en casa (2021). En fin, los efectos de haber asumido e implementado el enfoque intercultural los veremos en las siguientes generaciones. 


\section{Referencias Bibliográficas.}

Cadena Tv (2021). Docentes del colegio Santa Isabel reclaman en contra del plan de educación intercultural bilingüe. https://web.facebook.com/CadenaTVHuancayo/ videos/envivo-huancayo-educaci\% $\mathrm{C}_{3} \%$ B3n-lo-rechazan-docentes-del-colegio-santa-isabelreclaman/746834009280434/?_rdc=1Q_rdr

Congreso de la República (2014). Ley 30220, Ley Universitaria. https://www.sunedu.gob.pe/ wpcontent/uploads/2017/04/Ley-universitaria-30220.pdf

Minedu (2020). Aprendo en casa. https://aprendoencasa.pe/\#/

Ministerio de Cultura (2015) Política Nacional para la Transversalización del Enfoque Intercultural. https://centroderecursos.cultura.pe/sites/default/files/rb/pdf/Politicanacional-para-la-transversalizacion-del-enfoque-intercultural-final.pdf

Sunedu (2020). Universidades Licenciadas. https://www.sunedu.gob.pe/lista-deuniversidades-licenciadas/

Vargas, Jorge Luis Yangali.(2017). Derroteros de la educación peruana en el XXI: interculturalizar, decolonizar y subvertir. Ensaio: Avaliação e Políticas Públicas em Educação, 25(97), 918-942. https://doi.org/10.159o/s0104-40362017002500988 